\title{
Rancang Bangun Tabloid Online Bestari dengan Fitur Pencarian berbasis Search Engine Teknologi menggunakan Metode Vector Space Model
}

\author{
Mentari Mas'ama Safitri ${ }^{*}{ }^{*}$, Nur Hayatin ${ }^{2}$, Yufis Azhar ${ }^{3}$ \\ 1,2,3Teknik Informatika/Universitas Muhammadiyah Malang \\ mentarims24@gmail.com ${ }^{* 1}$, noorhayatin@gmail.com², yufis.azhar@gmail.com³
}

\begin{abstract}
Abstrak
Bestari merupakan lembaga pers mahasiswa yang merupakan media utama untuk menyuarakan dan mendokumentasikan berbagai kegiatan yang dilakukan sivitas akademika Universitas Muhammadiyah Malang. Bestari juga memliki tabloid online yang dapat diakses oleh mahasiswa, namun tabloid online Bestari Universitas Muhammadiyah Malang saat ini belum memiliki fitur pencarian, sehingga pengguna kesulitan untuk mendapatkan informasi sesuai dengan yang diinginkan. Berdasarkan masalah terse but pembangunan aplikasi Tabloid Online Bestari Universitas Muhammadiyah Malang dengan fitur pencarian berbasis search engine ini bertujuan untuk memberikan kemudahan kepada pengguna khususnya mahasiswa Universitas Muhammadiyah Malang dalam melakukan pencarian. Pada studi kasus ini metode Vector Space Model digunakan untuk memodelkan kumpulan berita dan keyword dari user dalam bentuk vektor yang telah di beri bobot dengan menggunakan metode pembobotan TF-IDF, kemudian akan di hitung kedekatan dari masing-masing dokumen dengan keyword dari user menggunakan cosine similarity.
\end{abstract}

Kata Kunci: Bestari, Search Engine, VSM, TF-IDF, Cosine Similarity

Abstract
Bestari is collage students' press agency that is the main media to show their opinion and document any activities that have already done by academic community of UMM. Bestari also has online tabloid that can be accessed by college students, but Bestari tabloid UMM does not currently have a search feature so the user difficult to get information needed. According to this problem, the developing of Tabloid Online Bestari UMM application that completed search feature with search engine based is purposed to give solution to the users especially for colledge students of UMM. This study used Vector Space Model (VSM) method to collect the news and keyword from the users in the form of vector that has been given scale used TF-IDF method, then the correlation of keyword with the document will be counted by using cosine similarity.

Keywords: Bestari, Search Engine, VSM, TF-IDF, Cosine Similarity

\section{Pendahuluan}

Penerapan teknologi digital dan jaringan komputer telah menyebabkan terjadinya "ledakan" informasi yang berkembang eksponensial. Hal ini menyebabkan Sistem temu kembali informasi (information retrieval=IR) mengalami kesulitan [1]. Information Retrieval (IR) merupakan bagian dari computer science yang berhubungan dengan pengambilan informasi dari dokumendokumen yang didasarkan pada isi dan konteks dari dokumen-dokumen itu sendiri. Informasi yang diinginkan pengguna direpresentasikan dalam bentuk query dan mengandung satu atau lebih term yang akan digunakan dalam pencarian.

Search engine atau mesin pencari merupakan teknik dari temu-kembali dalam menemukan dokumen dan sekaligus mengeksekusi algoritma peringkat dalam menampilkan dokumen. Pengguna dapat mencari halaman web yang dibutuhkan melalui search engine. Search engine tidak lain sebuah mesin pencari yang ulet dan teliti, yang melakukan eksplorasi atas informasiinformasi yang di-request tanpa memandang kapan, di mana dan oleh siapa itu dilakukan. Mesin pencari menggunakan indeks (yang sudah dibuat dan disusun secara teratur) untuk mencari file setelah pengguna memasukkan kriteria pencarian. Indexing atau pengindeksan merupakan proses membangun basis data indeks dari koleksi dokumen. Indexing dilakukan terhadap dokumen sebelum pencarian dilakukan [2]. 
Berita dapat dikatakan sebagai kebutuhan pokok dalam diri seseorang. Karena manusia hidup pasti membutuhkan informasi. Penyebaran berita sekarang ini juga diiringi dengan kemajuan teknologi. Masyarakat bisa dengan mudah mengakses berita sebagai sumber informasi melalui media cetak dan elektronik. Perkembangan teknologi media elektronik mendukung penyebaran informasi melalui akses internet dari gadget oleh para pengguna. Mudahnya akses ini memerlukan keakuratan dalam hasil pencarian. Kecanggihan inilah yang digunakan oleh para instansi termasuk universitas untuk menyebarkan informasi.

Tabloid online Bestari Universitas Muhammadiyah Malang saat ini belum memiliki fitur pencarian, sehingga pengguna kesulitan untuk mendapatkan informasi sesuai dengan yang diinginkan. Berdasarkan masalah tersebut pembangunan aplikasi Tabloid Online Bestari Universitas Muhammadiyah Malang dengan fitur pencarian berbasis search engine teknologi ini bertujuan untuk memberikan kemudahan kepada pengguna khususnya mahasiswa Universitas Muhammadiyah Malang dalam melakukan pencarian berita. Dalam penelitian yang dilakukan oleh Heninggar Septiantri yang membandingkan metode LSA (Latent Semantic Analysis) dan VSM (Vector Space Model) mengenai sistem penilai jawaban esai otomatis Bahasa Indonesia, didapatkan dari hasil uji coba bahwa secara keseluruhan rata-rata korelasi nilai VSM-manusia lebih tinggi dari LSA-manusia [3]. Oleh karena itu metode yang akan digunakan untuk penelitian ini adalah metode Vector Space Model.

Vector Space Model adalah suatu metode untuk merepresentasikan sistem temu kembali ke dalam vektor dan memperhitungkan fungsi similarity dalam proses pencocokan beberapa vektor [3]. Untuk melakukan perhitungan fungsi similarity terlebih dahulu akan di lakukan perhitungan pembobotan dari masing-masing dokumen dan keyword menggunakan Metode Pembobotan TF-IDF. Metode TF-IDF (Term Frequency-Inverse Document Frequency) merupakan suatu cara untuk memberikan bobot hubungan suatu kata (term) terhadap dokumen [4]. Metode ini menggabungkan dua konsep untuk perhitungan bobot yaitu, frekuensi kemunculan sebuah kata didalam sebuah dokumen tertentu dan inverse frekuensi dokumen yang mengandung kata tersebut [5].

Pada studi kasus ini metode Vector Space Model (VSM) digunakan untuk memodelkan kumpulan berita dan keyword dari user dalam bentuk vektor yang telah di beri bobot dengan menggunakan metode pembobotan TF-IDF, kemudian akan di hitung kedekatan dari masingmasing dokumen dengan keyword dari user menggunakan cosine similarity. Untuk proses perangkingan hasil pencarian berita pada mesin pencari ini tidak hanya dilihat dari kedekatan antara keyword dan kumpulan berita, tetapi juga akan ditambahkan proses perhitungan prosentase untuk parameter tanggal posting dan jumlah viewer agar dapat menampilkan hasil dari pencarian berita yang sesuai dengan input-an dari user.

\section{Metode Penelitian}

\subsection{TF-IDF (Term Frequency - Inverse Term Frequency)}

Term Frequency adalah frekuensi dari kemunculan kata dari sebuah dokumen yang bersangkutan. Semakin besar jumlah kemunculan suatu term yang terdapat dalam dokumen, semakin besar pula bobotnya atau akan memberikan nilai kesesuaian yang semakin besar [6]. Rumus Term Frequency adalah Persamaan 1 [4].

$$
w_{t, d}=\left\{\begin{array}{cl}
1+\log _{10} t f_{t, d}, & \text { if } t f_{t, d}>0 \\
0, & \text { if } t f_{t, d}=0
\end{array}\right.
$$

Inverse Document Frequency merupakan perhitungan dari pendistribusian kata atau term secara luas pada koleksi dokumen yang bersangkutan. Semakin sedikit frekuensi dokumen yang mengandung kata atau term tertentu, maka nilai dari IDF semakin besar [5]. Rumus Inverse Document Frequency adalah Persamaan 2 [4].

$$
i d f_{t}=\log _{10}\left(\frac{N}{d f_{t}}\right)
$$

Sehingga bobot akhir suatu term adalah dengan mengalikan keduanya, yaitu $\mathrm{tf} x$ idf seperti pada Persamaan 3 [3].

$$
W_{d, t}=t f_{d, t} x i d f_{t}
$$

REPOSITOR, Vol. 2, No. 5, Mei 2020: 611-618 


\subsection{Vector Space Model (VSM)}

Metode Ruang Vektor pada Gambar 1 adalah suatu metode untuk merepresentasikan sistem temu kembali informasi. Relevansi dokumen dengan query dianggap sebagai ukuran kesamaan antara vektor dokumen dengan vektor query. Semakin sama antara vektor dokumen dengan vektor query maka dokumen dianggap semakin relevan dengan query.

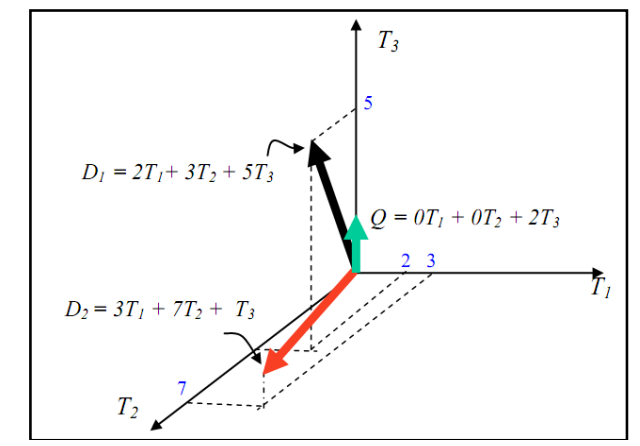

Gambar 1. Representasi Dokumen dan Query pada Ruang Vektor (Sumber: Mandala dan

Setiawan, 2002)

Perhitungan kesamaan antara vektor query dan vektor dokumen dilihat dari sudut yang terkecil. Sudut yang dibentuk oleh dua buah vektor dapat dihitung dengan melakukan perkalian dalam (inner product), sehingga rumus Cosine Similarity adalah Persamaan 4 [3].

$$
\operatorname{similarity}\left(\bar{d}_{j}, \bar{q}\right)=\frac{\bar{d}_{j} \cdot \bar{q}}{\left|\bar{d}_{j}\right| \cdot|\bar{q}|}=\frac{\sum_{i=1}^{t}\left(w_{i j} \cdot w_{i q}\right)}{\sqrt{\sum_{i=1}^{t} w_{i j}^{2} \cdot \sum_{i=1}^{t} w_{i q}^{2}}}
$$

Proses dilakukannya perangkingan dokumen dianggap sebagai proses pemilihan vektor dari suatu dokumen yang dekat dengan vektor dari query tersebut, kedekatan ini diindikasikan dari sudut yang dibentuk. Nilai cosine yang cenderung besar membuktikan bahwa dokumen cenderung sesuai query. Nilai cosine sama dengan 1 menyatakan bahwa dokumen sesuai dengan query [4].

\subsection{Recall dan Precision}

Recall digunakan untuk dokumen terpanggil yang relevan dengan query yang dimasukkan pengguna dalam sistem temu balik informasi. Recall terhubung dengan kemampuan sistem untuk menemukan dokumen relevan. Recall adalah bagian dari proses temu balik informasi yang bisa digunakan sebagai alat ukur untuk tingkat efektivitas suatu sistem. Recall berhubungan dengan kemampuan sistem memanggil dokumen relevan, sedangkan precision berkaitan dengan kemampuan sistem untuk tidak memanggil dokumen tidak relevan. Sebenarnya recall sulit diukur karena jumlah semua dokumen relevan yang terdapat dalam database sangat besar. Oleh karena itu precision yang menjadi suatu ukuran yang digunakan untuk memberika nilai keefektifan suatu sistem. Precison adalah jumlah frekuensi dokumen yang relevan dari jumlah frekuensi dokumen yang ditemukan oleh sistem. Presisi juga merupakan cara mengukur tingkat efektivitas sistem temu balik informasi [7].

Recall menemukan seluruh dokumen yang relevan dalam koleksi. Recall dapat dihitung dengan Persamaan 5 [8].

$$
\text { Recall }=\frac{\text { Jumlah dokumen relevan yg terpang gil }}{\text { Jumlah dokumen relevan yg ada di dalam database }} \times 100
$$

Nilai recall tertinggi adalah 1, yang berarti seluruh dokumen dalam koleksi berhasil ditemukan.

Precision hanya menemukan dokumen yang relevan saja dalam koleksi. Precision dapat dihitung dengan Persamaan 6 [8]. 


$$
\text { Precision }=\frac{\text { Jumlah dokumen relevan yg terpang gil }}{\text { Jumlah dokumen relevan yg terpang gil dalam pencarian }} \times 100
$$

Nilai precision tertinggi adalah 1, yang berarti seluruh dokumen yang ditemukan adalah relevan.

\subsection{Gambaran umum aplikasi}

Pada tahapan ini dilakukan analisa desain aplikasi search engine yang akan dibangun. Analisis sistem akan digambarkan dengan diagram alur, agar alur proses sistem dapat lebih mudah dipahami Gambar 2 merupakan rancangan proses sistem "Tabloid Online Bestari dengan Fitur Pencarian berbasis Search Engine Teknologi".

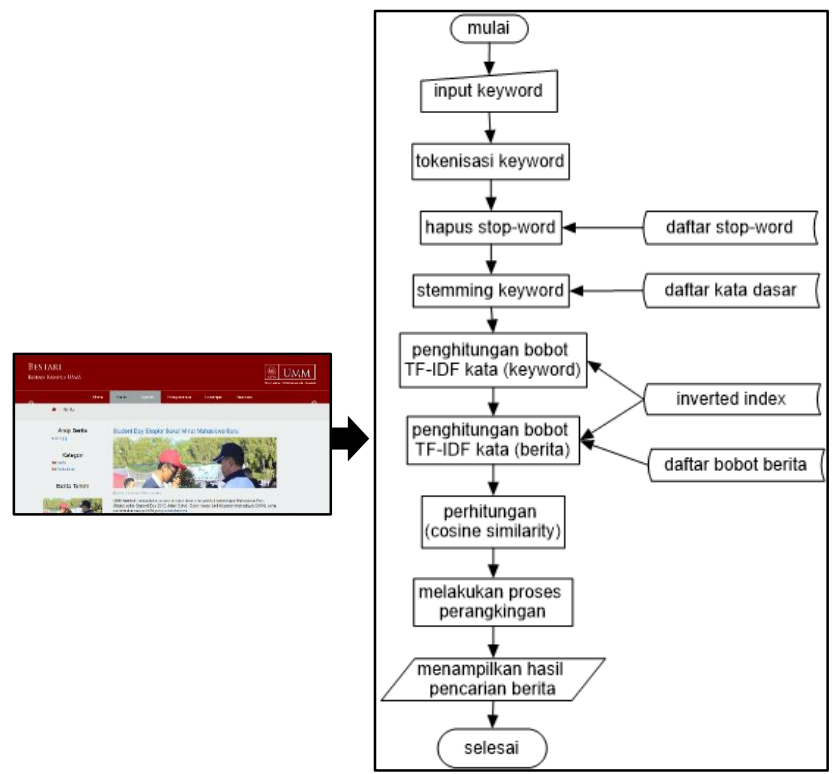

Gambar 2. Perancangan Alur Proses Sistem "Tabloid Online Bestari dengan Fitur Pencarian berbasis Search Engine Teknologi"

Deskripsi keterangan untuk Gambar 2 diatas adalah sebagai berikut, user memasukkan keyword untuk melakukan pencarian, setelah keyword dimasukkan dilakukan tahap pemotongan teks input (keyword) berdasarkan tiap kata yang menyusunnya yang disebut dengan tokenisasi. Kemudian dilakukan penghapusan kata umum dan dianggap tidak memiliki makna (stopword), selanjutnya dilakukan proses stemming yaitu untuk menemukan kata dasar dari sebuah kata. Setelah melakukan semua tahapan di atas, dilanjutkan ke tahapan berikutnya yaitu perhitungan pembobotan suatu kata dari keyword yang dimasukkan oleh user dan kata dari dokumen berita yang didapatkan dari tabloid bestari menggunakan metode pembobotan kata TF-IDF (Term Frequency-Inverse Document Frequency. Setelah proses perhitungan, dilakukan pengurutan dokumen sesuai dengan hasil perhitungan cosine similary, dimana semakin besar hasilnya maka jarak antara dokumen terhadap keyword tersebut semakin dekat, selain itu akan ditambahkan proses perhitungan prosentase untuk parameter tanggal posting dan jumlah viewer agar dapat menampilkan hasil dari pencarian berita yang sesuai dengan input-an dari user. Jadi hasil dari dokumen terurut yang akan ditampilkan oleh sistem tidak hanya dilihat dari kemiripan antar dokumen terhadap keyword, tetapi juga akan disesuaikan dengan tanggal posting dan jumlah viewer.

\subsection{Diagram Alir Halaman User}

Deskripsi keterangan untuk Gambar 3 diatas adalah sebagai berikut, user akan masuk ke halaman user. Pada halaman user terdapat 2 fitur, yaitu pencarian dan berita. Jika user memilih fitu pencarian, maka user akan melakukan input prosentase untuk perhitungan tanggal dan jumlah view, sebelumnya untuk prosentase perhitungan cosine similarity sudah diset $100 \%$, jadi jika user tidak melakukan input prosentase tanggal dan viewer, otomatis sistem akan menganggap prosentase tanggal dan viewer adalah $0 \%$. Setelah itu input keyword untuk 
melakukan pencarian, kemudian dilakukan proses perhitungan cosine similarity, tanggal posting dan jumlah viewer (jika prosentase sudah terisi). Selanjutnya sistem akan menampilkan hasil dari pencarian berita. Jika tidak, maka user bisa memilih fitur lihat berita yang dapat menampilkan kumpulan data berita yang terdapat pada sistem ini.

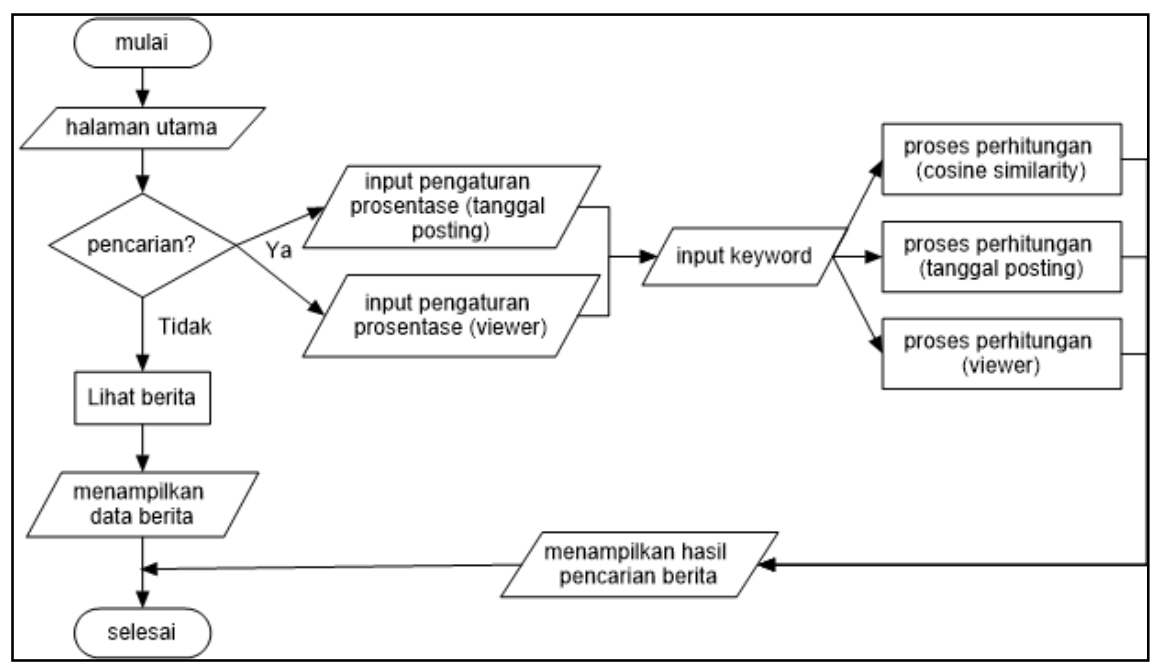

Gambar 3. Diagram Alir Halaman User

\subsection{Diagram Alir Halaman Admin}

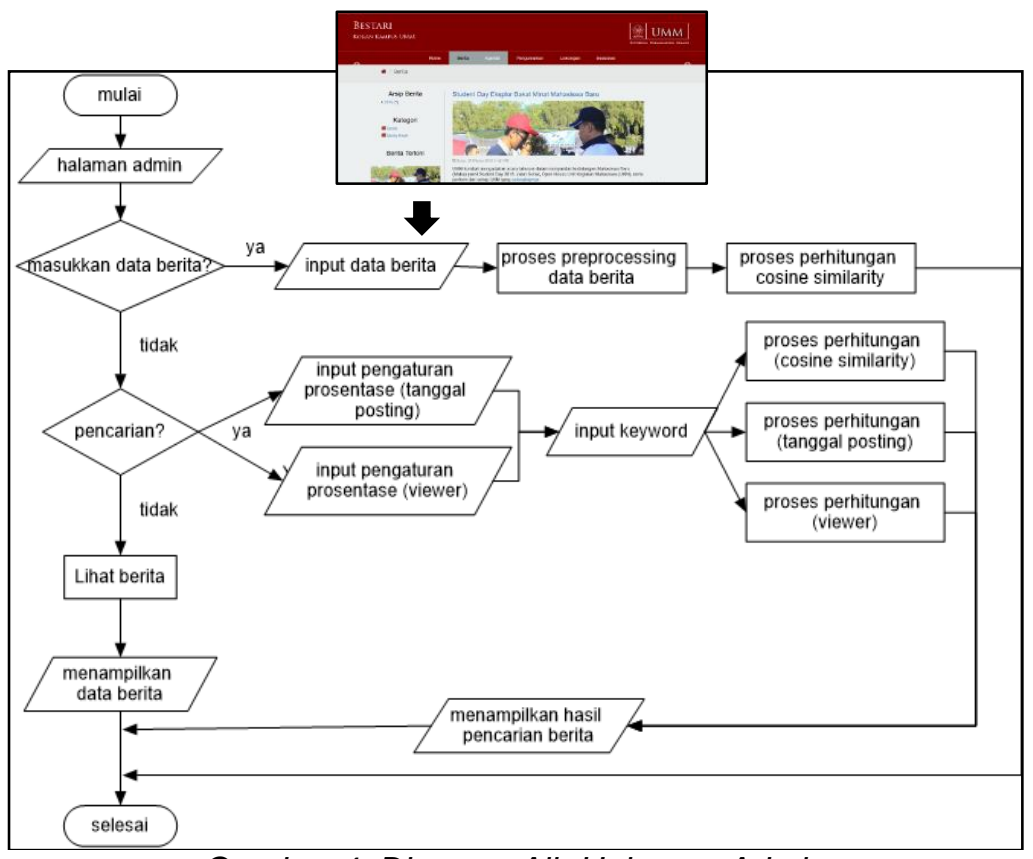

\section{Gambar 4. Diagram Alir Halaman Admin}

Deskripsi keterangan untuk Gambar 4 diatas adalah sebagai berikut, setelah melakukan login sebagai admin, kemudian akan masuk ke halaman admin. Pada halaman admin ada beberapa fitur, yang pertama adalah fitur untuk melakukan input data berita. Jika admin memilih fitur tersebut, selanjutnya admin akan memasukkan data berita (data berita yang akan dimasukkan diambil dari data berita pada koran bestari UMM), setelah data berita dimasukkan akan dilakukan proses preprocessing pada data berita, kemudian yang terakhir akan dilakukan perhitungan bobot pada masing-masing kata yang terdapat pada data berita dan dilakukan perhitungan cosine similarity-nya. Jika fitur untuk melakukan input data berita tidak dipilih, maka akan dilanjutkan pada fitur selanjutnya, yaitu fitur pencarian. Jika iya admin input prosentase untuk perhitungan tanggal dan jumlah view, sebelumnya untuk prosentase perhitungan cosine 
similarity sudah diset $100 \%$, jadi jika tidak melakukan input prosentase tanggal dan viewer, maka otomatis sistem akan menganggap prosentase tanggal dan viewer adalah $0 \%$. Setelah itu input keyword untuk melakukan pencarian, kemudian dilakukan proses perhitungan cosine similarity, tanggal posting dan jumlah viewer (jika prosentase sudah terisi). Selanjutnya sistem akan menampilkan hasil dari pencarian berita. Jika kedua fitur diatas tidak dipilih, maka admin bisa memilih fitur lihat berita yang dapat menampilkan kumpulan data berita yang terdapat pada sistem ini.

\section{Hasil Penelitian dan Pembahasan}

Pengujian dilakukan untuk mengukur kemampuan atau tingkat kinerja aplikasi dilakukan dengan 10 kata kunci yang telah ditetapkan, dimana hasil dari pencarian yang menggunakan metode cosine similarity dengan prosentase perhitungan sebesar $100 \%$ dari masing-masig keyword akan dievaluasi nilai dari precision dan recall untuk mengetahui tingkat kinerja dari aplikasi. Tabel 1 merupakan hasil dari perhitungan precision dan recall.

Tabel 1. Hasil Perhitungan Precision dan Recall

\begin{tabular}{cccc}
\hline No. & Keyword & Precision (\%) & Recall (\%) \\
\hline 1 & Teknik Informatika & $\frac{4}{27} \times 100 \%=14,81$ & $\frac{4}{4} \times 100 \%=100$ \\
2 & Asupan Gizi & $\frac{2}{11} \times 100 \%=18,19$ & $\frac{2}{2} \times 100 \%=100$ \\
3 & Kapal Militer & $\frac{1}{11} \times 100 \%=9,090$ & $\frac{1}{1} \times 100 \%=100$ \\
4 & Mutu Pengajar & $\frac{10}{120} \times 100 \%=8,334$ & $\frac{10}{10} \times 100 \%=100$ \\
5 & Negeri Indonesia & $\frac{42}{176} \times 100 \%=23,863$ & $\frac{42}{42} \times 100 \%=100$ \\
6 & Mahasiswa Wirausaha & $\frac{14}{183} \times 100 \%=7,650$ & $\frac{14}{14} \times 100 \%=100$ \\
7 & Luar Negeri & $\frac{4}{69} \times 100 \%=5,797$ & $\frac{4}{4} \times 100 \%=100$ \\
8 & Hukuman Mati & $\frac{13}{78} \times 100 \%=16,67$ & $\frac{13}{13} \times 100 \%=100$ \\
9 & Bangsa Indonesia & $\frac{43}{164} \times 100 \%=26,219$ & $\frac{43}{43} \times 100 \%=100$ \\
10 & Potensi Diri & $\frac{8}{82} \times 100 \%=9,756$ & $\frac{8}{8} \times 100 \%=100$ \\
\hline & Jumlah & 140,379 & 1000 \\
\hline
\end{tabular}

Dari hasil uji perhitungan yang dipaparkan pada Tabel 1 dapat dilihat rata-rata dari nilai precision dan recall. Nilai rata-rata precision dari aplikasi berdasarkan uji coba terhadap keyword adalah 0,1403 , atau bisa dikatakan aplikasi pencarian tabloid online bestari ini memiliki tingkat keakuratan dengan persentase $14,03 \%$. Nilai precision yang terlalu kecil dikarenakan sistem menggunakan metode pencarian cosine similarity, pada metode ini sistem hanya bisa membandingkan tingkat kemiripan antara keyword dengan dokumen berita yang ada, tanpa melihat persamaan makna antara term yang ada pada keyword dengan term yang ada pada dokumen berita. Sehingga pada contoh pencarian pertama untuk keyword "Teknik Informatika", jumlah dokumen relevan yang terpanggil dalam pencarian sebanyak 27 dari 300 data berita yang ada, sedangkan jumlah dokumen relevan yang terpanggil sesuai dengan keyword "Teknik Informatika", sebanyak 4 data berita dari 27 dokumen relevan yang terpanggil. Untuk nilai recall dari pengujian ini dengan menggunakan metode cosine similarity menghasilkan nilai recall yang tinggi, karena nilai dari jumlah dokumen relevan yang terpanggil sama besar dengan jumlah dokumen relevan yang ada didalam database. Sehingga menghasilkan nilai recall sebesar $100 \%$.

\section{Kesimpulan}

Berikut ini merupakan kesimpulan dari implementasi dan uji coba terhadap aplikasi pencarian berita pada tabloid online bestari yang telah dirancang. Dengan menggunakan metode 
Vector Space Model aplikasi ini mampu melakukan pencarian terhadap dokumen berita yang ada pada tabloid bestari Universitas Muhammadiyah Malang. Berdasarkan hasil uji coba terhadap 10 keyword dimana nilai rata-rata tingkat keakuratan aplikasi ini terhadap hasil pencarian mencapai nilai persentase $14,03 \%$. Sedangkan tingkat kemampuan aplikasi untuk menampilkan semua data berita yang relevan dengan keyword mencapai nilai persentase sebesar $100 \%$. Aplikasi dapat memudahkan user dalam mencari informasi mengenai berita seputar kampus Muhammadiyah Malang dan berbagai kegiatan yang mahasiswa, serta tips dan saran untuk kesehatan

\section{Saran}

Untuk pengembangan lebih lanjut mengenai aplikasi pencarian pada tabloid online bestari Universitas Muhammadiyah Malang ini, diberikan saran-saran sebagai berikut Aplikasi ini tidak hanya bisa melakukan pencarian dokumen dalam bahasa Indonesia, tetapi juga bisa dilakukan pencarian dokumen dalam bahasa Inggris. Aplikasi ini dapat dikembangkan menggunakan metode lain yang bisa memberikan tingkat keakuratan hasil pencarian yang lebih tinggi dibandingkan dengan metode sebelumnya. Dan aplikasi ini dapat dikembangkan menggunakan metode lain yang bisa melakukan pencarian tidak hanya menggunakan tingkat kemiripan suatu dokumen, tetapi juga bisa melakukan pencarian berdasarkan persamaan makan.

\section{Daftar Notasi}

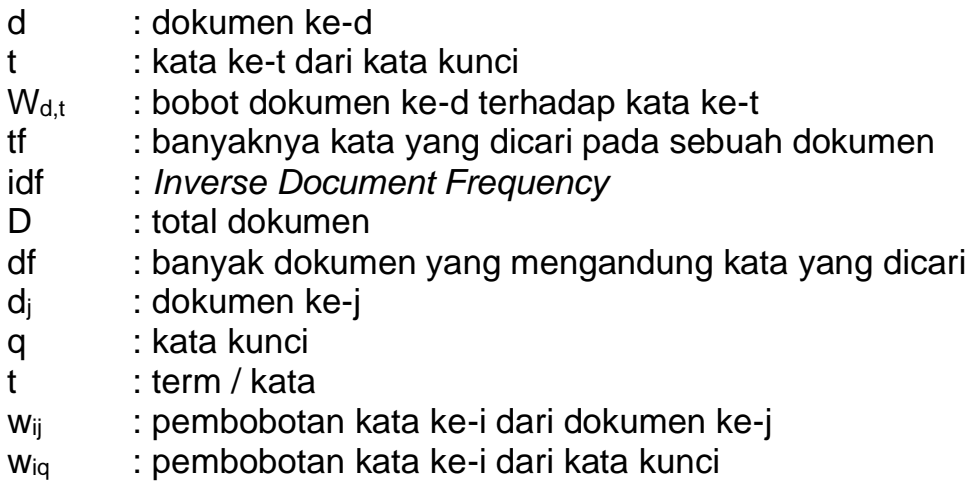

\section{Referensi}

[1] Aminx, F. (2012). Sistem Temu Kembali Informasi dengan Metode Vector Space Model. Jurnal Sistem Informasi Bisnis 02 , 78-83.

[2] Fitri, M. (2013). Perancangan Sistem Temu Balik Informasi dengan Metode Pembobotan Kombinasi TF-IDF untuk Pencarian Dokumen Berbahasa Indonesia.

[3] Darmawan, H. A., Wurijanto, T., \& Masturi, A. (2010). Rancang Bangun Aplikasi Search Engine Tafsir Al-Qur'an Menggunakan Teknik Text Mining Dengan Algoritma VSM (Vector Space Model).

[4] Karmayasa, O., \& Mahendra, I. B. (n.d.). Implementasi Vector Space Model dan Beberapa Notasi Metode Term Frequency Inverse Document Frequency (TF-IDF) pada Sistem Temu Kembali Informasi.

[5] Hamzah, A. (2009). Temu Kembali Informasi Berbasis Kluster untuk Sistem Temu Kembali Informasi Teks Bahasa Indonesia. Jurnal Teknologi.

[6] (2014, september 25). Retrieved from rahmadya: https:/rahmadya.com/2014/09/25/termfrequency-dan-invers-document-frequency-tf-idf/

[7] (2010, juni 9). Retrieved from repository.usu.ac.id: http://repository.usu.ac.id/bitstream/handle/123456789/17855/Chapter\%20II.pdf

[8] Wibowo, A. (2011). Pengujian Kerelevanan Sistem Temu Kembali Informasi. 
REPOSITOR, Vol. 2, No. 5, Mei 2020: 611-618 